\title{
Indoor Air Quality in a Real Operating Theatre under Effective Use Conditions
}

\author{
Carla Balocco1, Giuseppe Petrone2, Giuliano Cammarata², Pietro Vitali³, \\ Roberto Albertini ${ }^{4}$, Cesira Pasquarella ${ }^{5}$ \\ ${ }^{1}$ Department of Industrial Engineering, University of Firenze, Firenze, Italy \\ ${ }^{2}$ Department of Industrial Engineering, University of Catania, Catania, Italy \\ ${ }^{3}$ Hospital Hygiene Unit, University Hospital of Parma, Parma, Italy \\ ${ }^{4}$ Department of Clinical and Experimental Medicine, University of Parma, Unit of Medical Immunology, \\ University Hospital of Parma, Parma, Italy \\ ${ }^{5}$ Department of Biomedical, Biotechnological and Translational Sciences, University of Parma, Parma, Italy \\ Email: gpetrone@dii.unict.it
}

Received 3 July 2014; revised 18 August 2014; accepted 1 September 2014

Copyright @ 2014 by authors and Scientific Research Publishing Inc.

This work is licensed under the Creative Commons Attribution International License (CC BY). http://creativecommons.org/licenses/by/4.0/

c) (†) Open Access

\section{Abstract}

The aim of this study is to investigate the impact of surgical staff on the indoor air quality in a unidirectional ventilation Operating Theatre (OT). Experimental measurements of particles and microclimate were acquired at rest and in operational conditions. The real OT (operational) use was simulated by a sham hip arthroplasty. CFD simulations were carried out outlining the studied environment used for experimental measurement campaign. A standard $k-\varepsilon$ closure scheme based on RANS equations was implemented to solve the velocity and pressure field using an eddy viscosity approach. Temperature and relative humidity distributions were also computed keeping into account sensible and latent heat sources inside the OT. An Euler-based approach was applied to solve the concentration fields of gaseous contaminant and small particles (up to $5 \mu \mathrm{m}$ in diameter) in the indoor air. An innovative strategy is proposed to estimate, by an iterative comparison between experimental data and numerical results, the emission rate of particles (differentiated by diameters) released by the occupants to be considered as source terms in the numerical model. Compliance with literature evidence concerning thermal and velocity fields and $\mathrm{CO}_{2}$ concentration was confirmed. From our analyses, some IAQ indexes were deduced, allowing monitoring of the local and overall OT air quality level supplied by the ventilating system during real operational conditions. The highest values of microbial air contamination were recorded during surgical activity; nevertheless, results showed the suitability of the ventilation system in providing the expected air quality.

\section{Keywords}

Experimental Measurements, Numerical Simulation, CFD, Real Operating Theatre, Particles, IAQ

How to cite this paper: Balocco, C., Petrone, G., Cammarata, G., Vitali, P., Albertini, R. and Pasquarella, C. (2014) Indoor Air Quality in a Real Operating Theatre under Effective Use Conditions. J. Biomedical Science and Engineering, 7, 866-883. 


\section{Indexes}

\section{Introduction}

The study of ventilation performance for indoor air quality (IAQ) and contaminant removal in Operating Theatres (OTs) connected to definition and quantification of the contaminant sources under effective use conditions is a complex task. Existing databases generally refer to constant particle mass emission of a person as a function of his/her activity. Several works analyze different sources and human activities causing high levels of indoor particle concentration, diffusion and re-suspension processes. Some authors [1] present studies of the influence of periodic bending movement of the surgeon on the air flow field and bacteria carrying particle distribution using a combined approach based on Eulerian RANS model, modified drift-flux and moving mesh. Brohus et al. [2] used smoke visualization and numerical simulations to evaluate the influence of medical staff movements on contaminant transport in an OT. In that study, bacteria attributed to the skin flake emission of staffs and patients are simulated as a gaseous contaminant. The most widely used experimental methods allow particle size calculation for discrete intervals, so as to check whether microclimatic and IAQ conditions are in compliance with standards and specific rules. Some authors have developed a useful method for determining individual emission rates from ambient air contaminant concentrations caused by multiple indoor sources [3]. Other studies provide sampling method integrated with statistical analysis [4]. Otherwise, it is widely argued that in cleanrooms and OTs [5] the main source of aerosol particles is people, building materials, furnishings and equipment. In a recent paper, bacteria sources are investigated [6] in a university classroom while occupied and vacant as concentration differences due to the two conditions. Other authors demonstrate that aerosol particles may be suspended in an occupied area but also deposited on interior surfaces, their emission from persons being mainly due to sneezing and coughing, skin and hair fragments [7]. Besides the influence of the airflow pattern, it has been demonstrated that particle dynamic behavior is strongly dependent on particle size and size-related forces [8] [9]. Chih-Shan Li et al. [10] carried out a series of field tests by active and passive sampling of air and surfaces measuring bacterial and fungal concentrations without referring to particle size and diameter. Another paper [11] based on particle counting combined with statistical analysis, evaluates the aerobic bacterial sedimentation and connected index of microbial air contamination. In that, results refer to different particle diameters but not to emission sources. Computational Fluid Dynamics (CFD) applications have been proved as an effective way to investigate airflow and contaminant dispersion in indoor environments of OTs and cleanrooms [12] [13]. Some authors [9] [14] investigated the best ventilation system to control particle dispersion, but without connection to particle dimensions. In a recent study [15], CFD simulation was used to examine the effectiveness of the laminar flow system for preventing infectious particles reaching surgical staff. In a previous study by the same authors [16], simulations were carried out using the Renormalization Group (RNG) $k$ - $\varepsilon$ turbulence model, assuming a released rate of bacteria-carrying airborne particulates from surgical staff of $100 \mathrm{BCP} / \mathrm{min}$ per person and for patients of $400 \mathrm{BCP} / \mathrm{min}$ per wound. In general, CFD simulation concerning aerosol particle transport and diffusion processes can be solved by three main different numerical approaches. The first method consists in solving the particle concentration field by using diffusion-transport equations based on "passive scalar transport” into which the vector of particle transport is the motion field of the fluid but gravitational effects and frictional forces on particle motion are disregarded; this can provide misleading results for particles with a diameter larger than 10 $\mu \mathrm{m}$. The second approach is the Eulerian-Eulerian method and the third is the Eulerian-Lagrangian. Both methods solve the airflow field based on the Eulerian approach, but the particle phases are treated differently. With the Eulerian-Eulerian method the particle concentration is directly solved keeping into account the gravitational effect in the transport term, while in the Eulerian-Lagrangian one ordinary differential equation is solved for any particle path, so that a time-consuming statistical work is then required to obtain the particle concentration. A modified drift-flux model based on the second approach has been applied to modelling particle transport [1] [17] [18]. At present, there are not many articles in the literature concerning numerical modelling in which the contaminant concentration for the IAQ analysis has been performed starting from sources of particle emission with a distribution dependent on particle diameter [19] [20]. However, national and international standards require, for environment classification, a particle count for diameter dimension. Actually, there is a lack of data concerning specific emission sources in terms of particles issued in time unit by people. A recent study provides the 
quantification of size-resolved particle concentrations in indoor air of a classroom under occupied and vacant conditions [19]. Another important numerical study provides information on airflow, particle deposition and movement in two different spaces equipped with displacement and mixing ventilation modes [20]. A discrete trajectory model combined with the Eulerian method is adopted for simulating the indoor aerosol particle concentration.

Our present study starts from an investigation aiming to obtain a distribution of emitted particles as a function of their diameter, assuming that the amount of particles mass emitted by a person in a time unit does not change with their size. Starting from this assumption, the distribution of emitted particles will consist of a larger number of a smaller size, and vice versa. Experimental measurements and numerical CFD simulations were carried out during simulated hip surgery. Our study, referring to results presented in recent work of the authors [21], investigates the thermo-fluid dynamics combined with the analysis of the concentration of diluted gas phase and particle aerosol dispersion in the air. Some IAQ indexes, widely used in the literature, were calculated as global and local values referring to the total volume of the room but also to the critical zones defined by ANSI/ASHRAE [22].

\section{Experimental Measurements}

Experimental investigations were conducted in a real orthopaedic OT of the University Hospital of Parma (Italy) referring to [23]-[26]. The HVAC system was working during all tests, supplying a constant incoming airflow rate into the room at the controlled temperature. Combined microclimatic and microbiological measurements were carried out, during two different OT conditions: "at rest" (i.e. room complete, with all services functioning and equipment installed and operable or operating, but without surgical and healthcare staff and the patient); "operational", i.e. all services and equipment functioning, medical staff surrounding the patient lying on the operating table, during simulated hip surgery lasting 20 - 25 minutes, sliding door opening and closing (Figure 1). The experimental campaign was carried out over a two day period, from 8 a.m. to 2 p.m. The sampling points are illustrated in Figure 2. For microclimate measurements, 1 hot wire anemometer, 1 air-temperature and humidity sensor, 1 globe thermometer and 1 differential pressure sensor were used. Microclimate instruments were connected to a radio master R-Log data logger system, which provides average values of the parameters measured as results of the calculations of the acquisition made every 2 seconds (mean, maximum and minimum values). For air active sampling, a particle counter (Climet CL 754) was used. The equipment can sample a volume of $75 \mathrm{l} / \mathrm{min}$ of air and gives the number of suspended particles, divided according to the diameter $(\geq 0.3 ; \geq 0.5$, $\geq 1.0 ; \geq 5.0 \mu \mathrm{m})$, allowing one to deduce particle concentration in the diameter ranges $(0.3-0.5 \mu \mathrm{m}) ;(0.5-1 \mu \mathrm{m})$; $(1-5 \mu \mathrm{m})$. The measurements were carried out in triplicate in "at rest" and "in operational" conditions. For each sampling point, an activation delay of 2 and a delay of 10 between each moment of aspiration of the triplicate sampling was applied. Table 1 reports some technical data of instruments used for the experimental campaign. Statistical analysis of the experimental microclimate data and percentage deviation with respect to the average values was carried out: results are shown in Table 2. Experimental data of air temperature and relative humidity

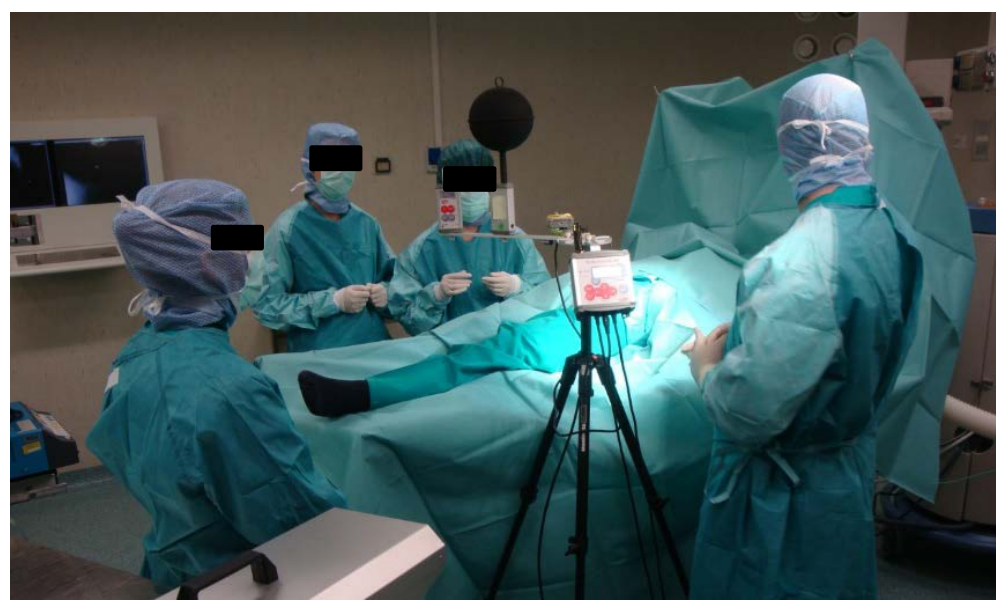

Figure 1. Medical staff (PhD students) simulating a hip surgery during the onsite investigations. 


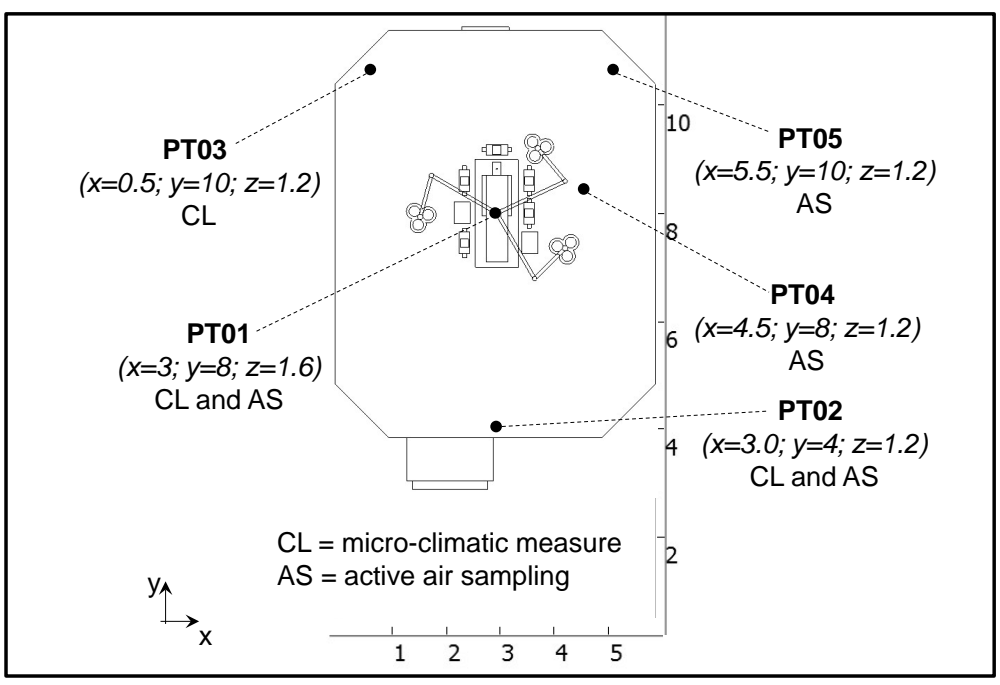

Figure 2. Indication of points used for experimental acquisitions and relative location in the chosen Cartesian system of coordinates.

Table 1. Technical data of instruments used for the experimental measurements.

\begin{tabular}{|c|c|c|c|c|}
\hline Microclimate & \multicolumn{2}{|c|}{ Range } & Resolution & Accuracy \\
\hline \multirow{2}{*}{$\begin{array}{l}\text { Air temperature and } \\
\text { air humidity sensors }\end{array}$} & Temperature & $-20^{\circ} \mathrm{C}-60^{\circ} \mathrm{C}$ & $\pm 0.1^{\circ} \mathrm{C}$ & \multirow{2}{*}{$\begin{array}{l} \pm 0.5^{\circ} \mathrm{C} \text { for } 5^{\circ} \mathrm{C}<\mathrm{T}<45^{\circ} \mathrm{C} \\
\pm 2 \% \text { for } 10 \%<\mathrm{RH}<90 \%\end{array}$} \\
\hline & Relative humidity & $0 \%-100 \%$ & $\pm 0.1 \%$ & \\
\hline Globe thermometer & Temperature & $-20^{\circ} \mathrm{C}-60^{\circ} \mathrm{C}$ & $\pm 0.1^{\circ} \mathrm{C}$ & $\begin{array}{c} \pm 0.2^{\circ} \mathrm{C} \text { for } 5^{\circ} \mathrm{C}<\mathrm{T}<45^{\circ} \mathrm{C} \\
\pm 0.4^{\circ} \mathrm{C} \text { for } \mathrm{T}<5^{\circ} \mathrm{C} \text { and } \mathrm{T}>45^{\circ} \mathrm{C}\end{array}$ \\
\hline Hot wire anemometers & Air velocity & $0-20 \mathrm{~m} / \mathrm{sec}$ & $\pm 0.01 \mathrm{~m} / \mathrm{s}$ & $\begin{array}{c}0-0.5 \mathrm{~m} / \mathrm{s}: \pm 5 \mathrm{~cm} / \mathrm{s} \\
0.5-1.5 \mathrm{~m} / \mathrm{s}: \pm 10 \mathrm{~cm} / \mathrm{s} \\
>1.5 \mathrm{~m} / \mathrm{s}: \pm 4 \%\end{array}$ \\
\hline Differential pressure sensors & Air pressure & 0 - $2.54 \mathrm{hPa}$ & $\pm 0.01 \mathrm{hPa}$ & $2 \%\left(20^{\circ} \mathrm{C}\right)$ \\
\hline \multicolumn{5}{|l|}{ Air active sampling } \\
\hline CLIMET CI 754 & \multicolumn{3}{|c|}{$\begin{array}{l}\text { Particle channel sizes: } 0.3,0.5,1.0,5.0 \mu \mathrm{m} . \\
\text { Size-resolution: exceeds requirements of ISO } 21501-4 \text {. } \\
\text { Concentration limit: } 13,300 \text { particles per liter (10\% coincidence). } \\
\text { Sampling volume: } 75 \text { liters per minute. }\end{array}$} & \\
\hline $\begin{array}{l}\text { DUO SAS } 360 \text { impactor } \\
\text { (Surface air sampler) }\end{array}$ & \multicolumn{3}{|c|}{$\begin{array}{l}\mathrm{D}_{50}(\mathrm{~mm}) \text { real } 2.0 \text {; ideal 1.52/1.45. } \\
\text { N. of holes: } 260(\mu \mathrm{m}) \\
\text { Diameter: } 1 \mathrm{~mm}^{2} . \\
\text { Surface: } 0.785 \mathrm{l} / \mathrm{min} . \\
\text { Flow rate: } 180 \mathrm{l} / \mathrm{min} . \\
\text { Velocity: } 17.34 \mathrm{~m} / \mathrm{s} \text {. }\end{array}$} & \\
\hline
\end{tabular}

are globally consistent: standard deviations are narrow, much more for temperature (less than $1^{\circ} \mathrm{C}$ ) than for relative humidity (less than 3 percentage points); normalized deviation does not exceed a 6\% threshold in any cases. At point PT01 (under the ceiling diffusers) a detected dispersion of the experimental data appears. This becomes very significant when air velocity measurements are considered. The much more pronounced variation of the measured velocity in PT01 during operational conditions can be due to the local airflow variation induced by medical staff movements. The medical staff also produces an increase in relative humidity levels, especially in the central zone (PT01). It appears that temperature values recorded during operational conditions are slightly lower than values in at rest conditions, because the local ventilation system operates in the full working phase. Analyzing particle concentration measurements, excluding PT01 at operational conditions for particles of 0.3 
Table 2. Experimental data of microclimatic parameters and statistical parameters computed by measurements. In the table, $X_{a v}$ represents the generic average value upon $N$ samples, $\sigma$ is the standard deviation and $X^{2}$ is the Chi-Square of Bevington error analysis.

\begin{tabular}{|c|c|c|c|c|c|c|c|c|c|}
\hline & & & $\mathrm{T}\left[{ }^{\circ} \mathrm{C}\right]$ & & $\mathrm{T}_{\mathrm{mr}}\left[{ }^{\circ} \mathrm{C}\right]$ & $\mathrm{U}[\mathrm{m} / \mathrm{s}]$ & & $\phi[\%]$ & \\
\hline & & PT01 & PT02 & РT03 & PT01 & PT01 & PT01 & PT02 & PT03 \\
\hline \multirow{6}{*}{ At rest } & $\boldsymbol{X}_{a v}$ & 21.2 & 21.4 & 21.3 & 21.6 & 0.29 & 63.2 & 61.5 & 61.9 \\
\hline & $\sigma_{(N-1)}$ & 0.76 & 0.33 & 0.42 & 0.43 & 0.03 & 2.70 & 1.08 & 1.45 \\
\hline & $\sigma_{N}$ & 0.72 & 0.31 & 0.40 & 0.41 & 0.03 & 2.56 & 1.02 & 1.37 \\
\hline & $\chi^{2}$ & 0.58 & 0.11 & 0.18 & 0.19 & 0.001 & 7.29 & 1.17 & 2.10 \\
\hline & $\sigma_{(N-1)} / X_{a v}$ & $3.6 \%$ & $1.5 \%$ & $2.0 \%$ & $2.0 \%$ & $10.9 \%$ & $4.3 \%$ & $1.8 \%$ & $2.3 \%$ \\
\hline & $\sigma_{N} / X_{a v}$ & $3.4 \%$ & $1.5 \%$ & $1.9 \%$ & $1.9 \%$ & $10.3 \%$ & $4.1 \%$ & $1.7 \%$ & $2.2 \%$ \\
\hline \multirow{6}{*}{ Operational } & $\boldsymbol{X}_{a v}$ & 20.3 & 21.4 & 21.2 & 20.9 & 0.26 & 66.8 & 61.6 & 62.3 \\
\hline & $\sigma_{(N-1)}$ & 0.80 & 0.33 & 0.41 & 0.66 & 0.10 & 2.86 & 1.14 & 1.45 \\
\hline & $\sigma_{N}$ & 1.11 & 0.45 & 0.57 & 0.91 & 0.14 & 2.78 & 1.57 & 2.00 \\
\hline & $\chi^{2}$ & 1.37 & 0.22 & 0.36 & 0.93 & 0.023 & 8.62 & 2.76 & 4.47 \\
\hline & $\sigma_{(N-1)} / X_{a v}$ & $4.1 \%$ & $1.6 \%$ & $2.0 \%$ & $3.2 \%$ & $41.3 \%$ & $4.4 \%$ & $1.9 \%$ & $2.4 \%$ \\
\hline & $\sigma_{N} / X_{a v}$ & $5.5 \%$ & $2.1 \%$ & $2.7 \%$ & $4.4 \%$ & $55.5 \%$ & $4.2 \%$ & $2.6 \%$ & $3.2 \%$ \\
\hline
\end{tabular}

$\mu \mathrm{m}$ diameter and PT05 at rest conditions for particles of $5 \mu \mathrm{m}$ diameter, particle distribution for each diameter is similar for the two OT use conditions at the different measurement points. As expected, the highest particle concentration values are during operational conditions. Referring to the absolute value, the higher differences between the two OT use conditions were checked at PT05 for each particle diameter, while the lower differences were checked at PT01. Particle concentration measured at PT01 for the two use conditions of OT and for each diameter, respects the standard limit imposed by the ISO5 at rest classification [24] [27] and Grade B EU-GMP clean-rooms classification (Annex 1), in accordance with EN ISO 14644, for both at rest and operational conditions. In particular, referring to the GMP at operational conditions it can be observed that: at PT01 the conditions imposed by Grade B are respected by all the various particles (for all different diameters) at operational conditions; concentration of $0.5 \mu \mathrm{m}$ diameter particles are inside the standard limits for operational conditions, but in particular at PT01, PT03, PT04 and PT05, it is higher than the suggested limits.

\section{Numerical Modelling}

The OT (120 $\mathrm{m}^{3}$ volume) exploited for experimental acquisitions was outlined for carrying out numerical simulations. The geometry of the model is reported in Figure 3. Some geometrical elements were used in order to simulate the medical staff and the patient, the lighting system (operating table, trolley and one electro-medical instrument). Two rectangular supply ceiling diffusers each of $0.56 \mathrm{~m}^{2}$ surface are located in the central zone of the ceiling. Each diffuser provides a constant flow rate of $3969 \mathrm{~m}^{3} \cdot \mathrm{h}^{-1}$ of fresh air, so that there are 66 air changes per hour in the room. Two groups of 14 conical outgoing grilles (cross-section of $0.0128 \mathrm{~m}^{2}$ ) are arranged over two smoothed corners of the room. Following indications given in ANSI/ASHRAE Standard 62.1-2004 and in ANSI/ASHRAE Standard 55-2004, the global OT air-volume (TV) was divided into 3 zones, labelled from now on as Breathing Zone (BZ, highlighted in pink in Figure 4), Occupied Zone (OZ, highlighted in blue in Figure 4) and Peripheral Zone (PZ, corresponding to TV-OZ). This allowed the computation of air quality indexes referring to each zones.

Numerical simulation models were built-up by commercial software allowing multi-physical analyses through solution of the related governing equations by using a FE-based method. Our analyses provided solutions for air velocity, temperature, relative humidity, carbon-dioxide concentration $\left(\mathrm{CO}_{2}\right)$, mean age of air and particulate 


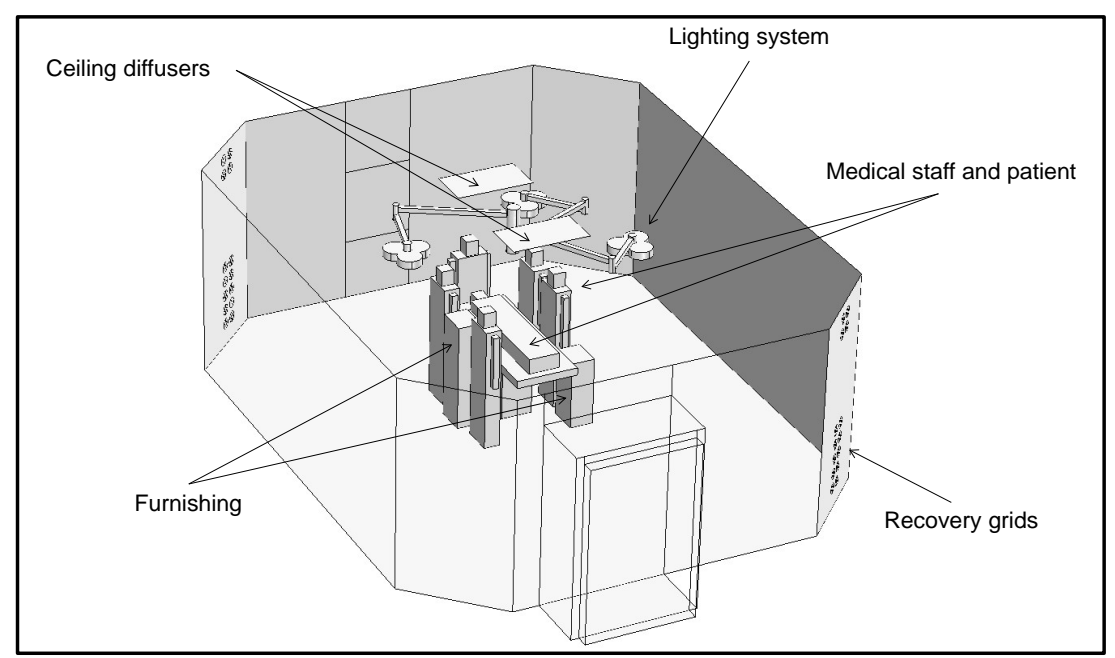

Figure 3. Geometry of the numerical model.

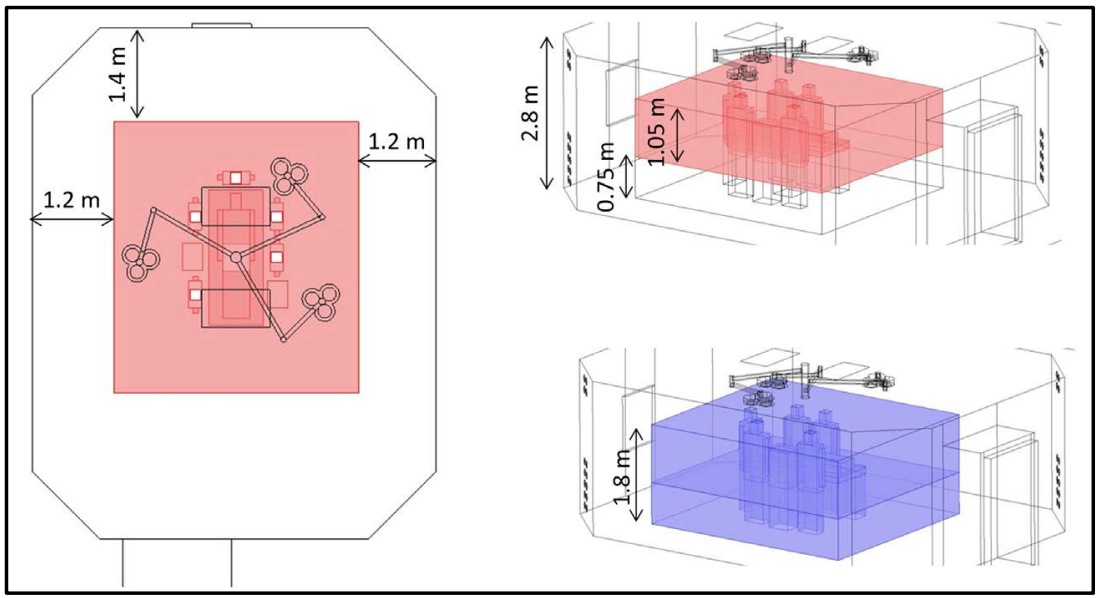

Figure 4. Indication of BZ (pink) and OZ (blue).

concentration for diameters $0.4,0.75,3 \mu \mathrm{m}$. These dimensions represent the average particle diameter referring to the particle diameter range that were experimentally measured $((0.3-0.5 \mu \mathrm{m}) ;(0.5-1 \mu \mathrm{m}) ;(1-5 \mu \mathrm{m}))$. The basic formulation of the PDE used for computations is:

$$
\frac{\partial(\rho \phi)}{\partial t}+\nabla \cdot(\rho \phi \mathbf{U})=\nabla \cdot(\Gamma \nabla \phi)+\Lambda
$$

where $\rho$ is the fluid density and $\mathbf{U} \equiv(u, v, w)$ is the velocity vector. For fluid-dynamical analysis, we considered a RANS approach for Newtonian fluid and incompressible flow, where a standard $k-\varepsilon$ method is applied to solve turbulence. Table 3 shows the analytical formulation of the different terms appearing in Equation (1), depending on the specific physic referring to.

Considering particulate diameters higher than $0.01 \mu \mathrm{m}$, Brownian diffusivity was considered negligible with respect to turbulent diffusivity that was assumed to be equal to the kinematic turbulent viscosity of air [28]. Adopting an Euler approach for solving particle concentration, the following settling velocity was added to the vertical component of the transport vector:

$$
\mathbf{w}_{S}=\frac{C_{c} \rho_{p} d_{p}^{2}}{18 \mu} \cdot \mathbf{g}
$$

$C_{c}$ being the Cunningham coefficient, $\rho_{p}$ and $d_{p}$ the particulate density and diameter, respectively. Source terms and values of physical properties appearing in conservation equations are listed in Table 4. 
Table 3. Analytical formulation of terms appearing in Equation (1), depending on the specific physic referring to.

\begin{tabular}{|c|c|c|c|}
\hline Equation & $\phi$ & $\Gamma$ & $\Lambda$ \\
\hline Continuity & 1 & 0 & 0 \\
\hline Momentum & $\mathbf{U}$ & $\mu+\mu_{T}$ & $-\nabla p+\mathbf{F}$ \\
\hline Turbulent kinetic energy & $k$ & $\mu+\mu_{T} / \sigma_{k}$ & $\frac{1}{2} \mu_{T}\left[\nabla \mathbf{U}+(\nabla \mathbf{U})^{\mathrm{T}}\right]^{2}-\rho \varepsilon$ \\
\hline Dissipation rate of kinetic energy & $\varepsilon$ & $\mu+\mu_{T} / \sigma_{\varepsilon}$ & $\frac{1}{2} C_{\varepsilon 1} \frac{\varepsilon}{k} \mu_{T}\left[\nabla \mathbf{U}+(\nabla \mathbf{U})^{\mathrm{T}}\right]^{2}-\rho C_{\varepsilon 2} \frac{\varepsilon^{2}}{k}$ \\
\hline Energy & $T$ & $\lambda / C_{p}$ & $\frac{Q_{S}}{C_{p}}$ \\
\hline Relative humidity & $R H$ & $\frac{\delta_{p} p_{s a t}}{\xi}+D_{w}$ & $\frac{Q_{L}}{\xi}$ \\
\hline Mean age of air & $\tau$ & $\Upsilon$ & $\rho$ \\
\hline $\mathrm{CO}_{2}$ concentration & $\mathrm{CO}_{2}$ & $\frac{D_{\mathrm{CO}_{2}}}{\rho}$ & 0 \\
\hline Particulate concentration & $C_{d_{i}}$ & $\frac{D+\varepsilon_{p}}{\rho}$ & 0 \\
\hline
\end{tabular}

Table 4. Physical properties of materials and source term values.

\begin{tabular}{cccccccc}
\hline \multirow{2}{*}{ Material } & $\rho$ & $\eta$ & $\lambda$ & $C_{p}$ & $F$ & $Q_{s}$ & $Q_{L}$ \\
\cline { 2 - 7 } & {$\left[\mathrm{kg} / \mathrm{m}^{3}\right]$} & {$[\mathrm{Pa} \cdot \mathrm{s}]$} & {$[\mathrm{W} /(\mathrm{m} \cdot \mathrm{K})]$} & {$[\mathrm{J} /(\mathrm{kg} \cdot \mathrm{K})]$} & {$\left[\mathrm{N} / \mathrm{m}^{3}\right]$} & {$[\mathrm{W}]$} & {$[\mathrm{W}]$} \\
\hline Glass (window, lamp) & 2500 & - & 1.00 & 800 & - & 4025 (lamps) & - \\
Wood (door) & 500 & - & 0.50 & 1000 & - & - & - \\
$\begin{array}{c}\text { Aluminium (operating table, } \\
\text { electro-medical case, lamp arms) }\end{array}$ & 2700 & - & 160 & 900 & - & - & - \\
Medical staff & 950 & - & 0.62 & 4180 & - & 73.3 & 58.6 \\
Patient & 950 & - & 0.62 & 4180 & - & 65.9 & 30.7 \\
Air & $p /(R T)$ & $2 \mathrm{E}-5$ & 0.04 & 1004 & $\rho g \beta \Delta T$ & - & - \\
\hline
\end{tabular}

For supplied air at the ceiling diffusers we assumed the following first-type boundary conditions: velocity magnitude $(1.97 \mathrm{~m} / \mathrm{s})$, turbulence intensity $(5 \%)$, temperature $\left(18^{\circ} \mathrm{C}\right)$, relative humidity $(60 \%), \mathrm{CO}_{2}(350 \mathrm{ppm})$ and mean age of air $(0 \mathrm{~s})$. For modeling persons breathing, we assumed a sinusoidal trend for inhaled/expired air and for $\mathrm{CO}_{2}$ emission rate into the room. In steady state simulations, we used the corresponding root mean square values as magnitude for chosen air and $\mathrm{CO}_{2}$ flow rate at the nose holes of the medical staff and patient. Adopted values in simulations were $2.0 \mathrm{~m}^{3} / \mathrm{h}$ (medical staff) and $0.3 \mathrm{~m}^{3} / \mathrm{h}$ (patient) for breathed airflow and $0.080 \mathrm{~m}^{3} / \mathrm{h}$ (medical staff) and $0.012 \mathrm{~m}^{3} / \mathrm{h}$ (patient) for $\mathrm{CO}_{2}$ emission rate. Outflow conditions were considered for all dependent variables at the recovery grids. At each solid/fluid interface, logarithmic wall functions were applied in the near wall airflow that was considered parallel to the wall and being in a wall offset equals one hundred viscous units. Turbulent production was assumed to equal dissipation at walls. For the remaining dependent variables we assumed impermeable/insulation conditions at walls, except in thermal analysis, where we applied a convective thermal flux, considering a heat exchange coefficient of $7.7\left(\mathrm{~W} / \mathrm{m}^{2} \cdot \mathrm{K}\right)$ and a constant temperature of $20^{\circ} \mathrm{C}$ for adjacent rooms. The occupants contribution for particle emission rate was applied as a boundary flux $\left[\mathrm{particle} /\left(\mathrm{m}^{2} \cdot \mathrm{s}\right)\right]$ at the occupants/surrounding air interfaces. The procedure adopted to assess the particulate flux depending on the particle dimension is explained in the next section. The governing equations together with their boundary conditions were spatially discretized on non-structured grids, made of second order tetrahedral elements. Steady state solutions of discrete equations were carried-out by applying an iterative dumped Newton-Raphson scheme [29] based on the discretized PDE linearization by a first-order Taylor expan- 
sion. Algebraic systems of equations coming from differential operator discretization were solved by a PARDISO package, a direct solver particularly efficient to solve unsymmetrical sparse matrixes by a LU decomposition method. The convergence criterion was set to $1 \mathrm{E}-5$. Time integration of governing equations for transient simulations was performed applying an Implicit Differential-Algebraic (IDA) solver [30], which uses variable-order and variable-step-size Backward Differentiation Formulas (BDF). Because the time-marching scheme is implicit, a nonlinear system of equations must be solved at each time step. The above-mentioned Newton algorithm was exploited to solve this nonlinear system of equations. Test grids were preliminarily carried out in order to adequately refine the computational grid to obtain mesh-independent results. All computations were carried out on a workstation with two 64-bit 6-core/12-thread processors speeding up to $2.3 \mathrm{GHz}$ of frequency and handling 128 GB of RAM.

\section{Use of Experimental Data for Numerical Model Implementation and Validation}

Experimental data were exploited both to provide data used for numerical model implementation and check simulation results reliability and validity. Microbiological measures of particle concentration were used to assess particle emission rates imposed as boundary conditions in the numerical models. Particle emission rate per person, distinguished for dimension, was not known a priori during our research. Zhao et al. [20] considered a constant generation rate of $0.0916 \mu \mathrm{g} / \mathrm{s}$ per person for each particle size group. For each particle dimension, referring to an assumed particle density of $1.05 \mathrm{E}-6 \mu \mathrm{g} / \mu^{3}$, scaling the emission rate by the particle volume, it is possible to obtain the related number of particles emitted by a person in the time unit. Quian et al. [19] used a different method to assess particulate emission rate, divided for different diameter, caused by the occupants in a classroom. They experimentally measured the particulate concentration at specific locations in the classroom for similar environmental conditions, but with and without people presence. They argued that difference in acquisitions could be attributed to emissions due to occupant contribution, and then proposed a particulate emission distribution as a function of particle diameter. The emission rate refers to how many particles of a specific dimension are supplied by one person in the time unit to the surrounding environment. The two above mentioned approaches used for particle source evaluation caused by occupants provide different results. In our investigation, we evaluated particle emission due to each occupant, differentiated for diameter dimension, exploiting the experimental acquisitions of particle concentration in the real OT with and without patient and medical staff presence. In particular, we applied a similar method used in [19] to assess the particle emission rate by occupants to be exploited in the numerical models. Otherwise, in our case we combined the available experimental data with results coming out from numerical simulations to assess the emission rate of particles per person depending on the particle dimension. The procedure used is given in the flow-chart diagram of Figure 5: the caption "sampling points" refers to points PT01, PT02, PT04 and PT05, "particle diameter range" means $(0.3-0.5 \mu \mathrm{m})$; $(0.5$ - 1 $\mu \mathrm{m}) ;(1-5 \mu \mathrm{m})$, and "average particle diameter" refers to the average values of the particle diameter $(0.4 ; 0.75$; $3 \mu \mathrm{m})$ computed for each of the previous ranges. Then the distribution of emission rate by occupants as a function of particle dimensions was assessed.

Comparison between experimental and numerical particles concentration due to occupants in the OT is shown in Figure 6. In this figure, experimental value (EXP) for each diameter $\left(d_{i}\right)$ represents the difference between average data $(A v)$ acquired for the at rest (rest) and operational (oper) conditions, computed as follows:

$$
E X P_{d_{i}}=A v\left\{E X P_{d_{i}}\right\}_{\text {oper }}-A v\left\{E X P_{d_{i}}\right\}_{\text {rest }}
$$

While the error bars are plotted by assuming the following:

$$
\begin{aligned}
& E r r_{d_{i}}^{+}=\max \left\{E X P_{d_{i}}\right\}_{\text {oper }}-\min \left\{E X P_{d_{i}}\right\}_{\text {rest }} \\
& E r r_{d_{i}}^{-}=\min \left\{E X P_{d_{i}}\right\}_{\text {oper }}-\max \left\{E X P_{d_{i}}\right\}_{\text {rest }}
\end{aligned}
$$

Numerical values plotted refer to the "final" particle emission rate per average diameter applied to the exposed person surfaces carried out from application of the computing procedure shown in Figure 5. Values of emission rate for diameter range are otherwise presented in Table 5, where values suggested in the previous literature are also reported. Some remarks follow. Despite an iterative application of our proposed "guess and check" procedure, experimental/numerical difference in particle concentration at point PT01 (under the ceiling diffusers) 


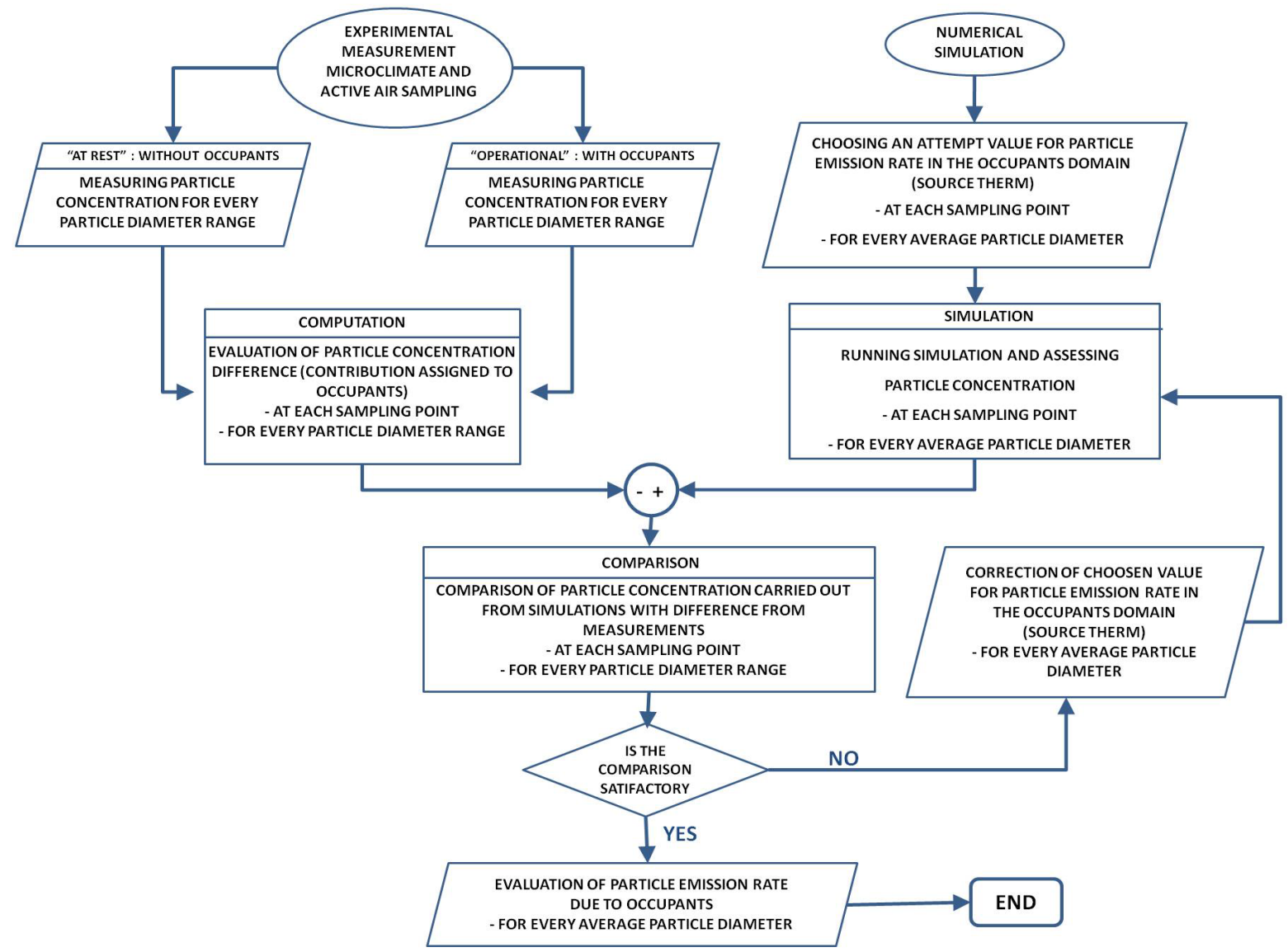

Figure 5. Flowchart of method used for estimating the occupants' particle emission rate per diameter by an iterative crosscomparison between numerical and experimental data.

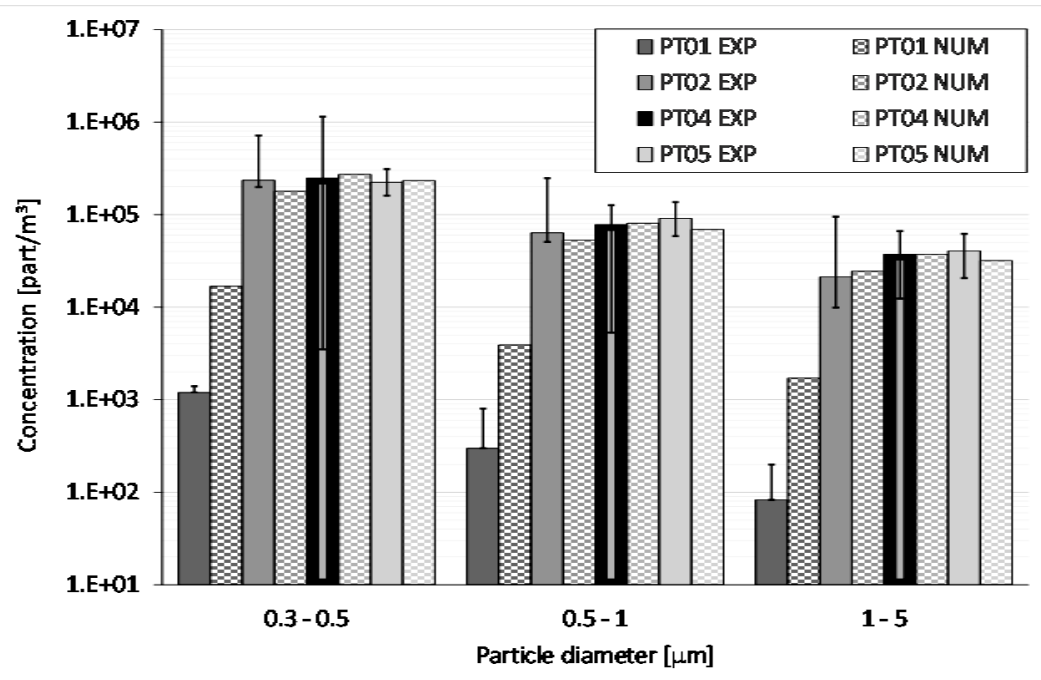

Figure 6. Particles concentration per diameter in different locations: comparison between experimental (plain colour bars) and numerical (chequered bars) values.

remained quite high; in particular, numerical model overestimates the particle contents in air at this location. Otherwise, a good agreement can be pointed out from comparison of particle concentration at the other different locations. Obtained results of particle emission rate per diameter and per person (Table 5), provide lower values 
with respect to those proposed by Quian et al. However, this was an expected result, because measurements by Quian [19] refer to a different indoor environment (university classroom) with different use conditions, occupied by students wearing "normal" clothes, very different from medical staff special clothing (see Figure 1). Microclimatic measurements were exploited to check the numerical modeling and results validity. Figure 7 shows comparison between experimental and simulated data on a T-RH plane for each measurement point: different colors concern different location of the experimental measurement points and the corresponding numerical values of the considered parameters.

A good agreement can be noted between microclimatic experimental data with numerical results with relative differences lower than $10 \%$. Numerical values globally stand within the range of measurement variation, foregrounding a good agreement with the experimental data. Comparison between microclimate experimental data with average parameter values suggested by Italian and International standards showed that [31]-[37] the average temperature values at probe locations are within the suggested limits. This is always confirmed for the "at rest" condition, but for the "operational" one the acquired values exceed the recommended thresholds due to medical staff presence and movements that produce local temperature and airflow modifications. The air velocity values globally fit standard limits, suggested for unidirectional flow.

\section{Results}

\subsection{Microclimate and $\mathrm{CO}_{2}$ Distribution}

This section aims to present and discuss simulation results. Two slides (vertical and horizontal, Figure 8) are selected to show the velocity field and one slice for the thermal map (horizontal, Figure 9). The high supply air velocity from unidirectional vertical down toward the surgical site, overcomes the buoyancy forces of the thermal plume from surgical staff around the surgical table. Near the wound site the air velocity is higher than 0.25 $\mathrm{m} / \mathrm{s}$ (Figure 8), even if the air velocity field is slightly deformed by thermal effect due to surgical lights. Thermal field inside the room is locally changed by surgical staff presence, equipment and surgical lights. However, the air temperature in the operating zone is less than $23.5^{\circ} \mathrm{C}$ and $20^{\circ} \mathrm{C}$ around the surgical table (Figure 9). In

Table 5. Particle emission rate (particles/s) from persons differentiated by diameter.

\begin{tabular}{|c|c|c|c|c|c|c|c|c|c|}
\hline & & \multicolumn{8}{|c|}{ Particle diameter $[\mu \mathrm{m}]$} \\
\hline & & 0.4 & 0.5 & 0.75 & 1 & 2 & 2.5 & 3 & 5 \\
\hline Present study & & $1.01 \mathrm{E}+05$ & & $2.96 \mathrm{E}+04$ & & & & $1.36 \mathrm{E}+04$ & \\
\hline Zhao & [part/s] & & & & $1.67 \mathrm{E}+05$ & & $1.07 \mathrm{E}+04$ & & $1.33 \mathrm{E}+03$ \\
\hline Quian & & & $3.95 E+06$ & & $7.58 \mathrm{E}+05$ & & $3.16 \mathrm{E}+05$ & 2.43 & +05 \\
\hline
\end{tabular}

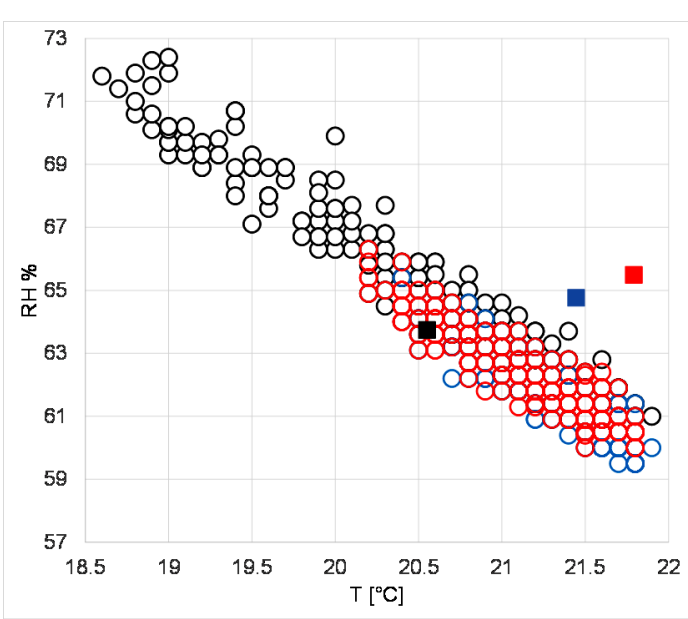

Figure 7. Comparison between experimental (circled) and simulated (squared) data on a T-RH plane for PT01 (black), PT02 (blue) and PT03 (red). 


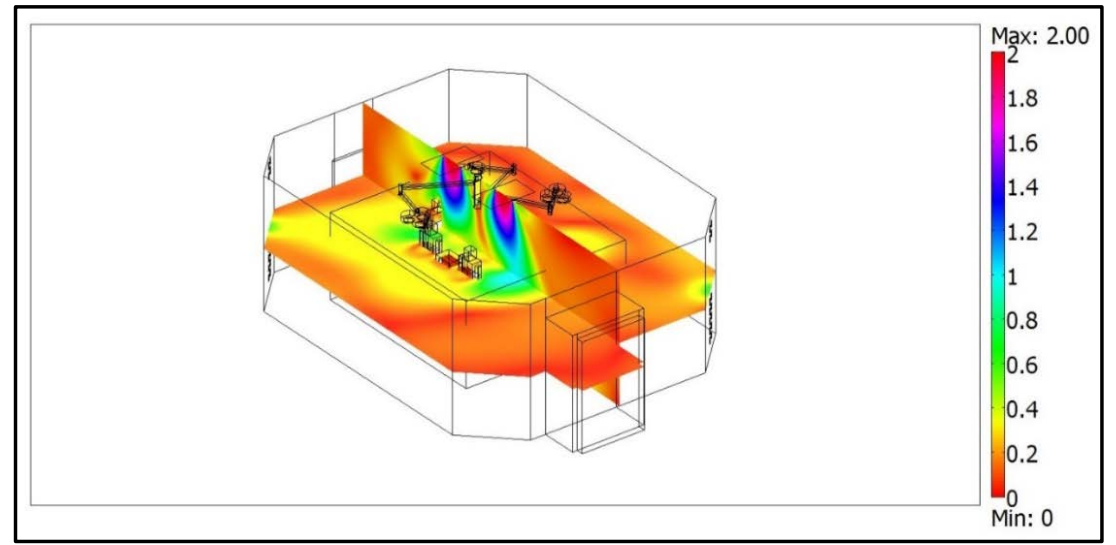

Figure 8. Air velocity field $(\mathrm{m} / \mathrm{s})$ on vertical slice $(x=3.0)$ and horizontal slice $(z=1.2)$.

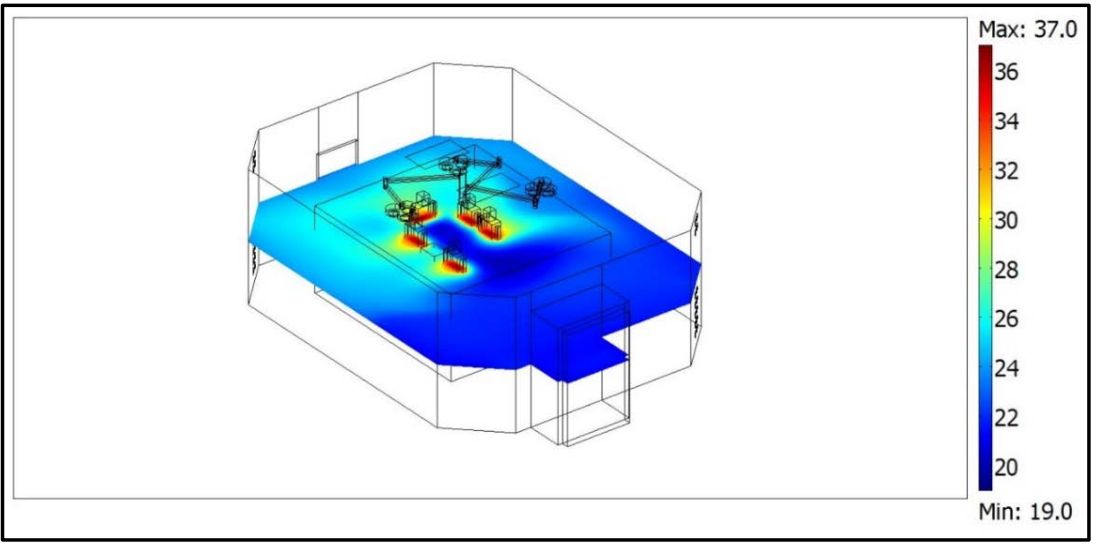

Figure 9. Air temperature distribution $\left({ }^{\circ} \mathrm{C}\right)$ on horizontal slice $(z=1.2)$.

Figure 10 the air relative humidity distribution is shown on a horizontal section of the room. The transport effect of the flow field is particularly evident: away from the surgical site thermal plume is not present and not even strong enough to rise up towards the ceiling, then air temperature and relative humidity stratification are not present in the global OT volume. Referring to the air freshness concept, the $\mathrm{CO}_{2}$ concentration shown in Figure 11 on a horizontal plane, is considerably below the critical limit of 3000 parts per million (ppm) in the global room volume and $1000 \mathrm{ppm}$ in the operating table zone.

The $\mathrm{CO}_{2}$ concentration is high only in the breathing zone where staffs are exhaling. The driving effect due to the velocity field is preponderant in spatial distributions of the scalar variables (temperature, relative humidity and $\mathrm{CO}_{2}$ concentration), so that a considerable similarity can be pointed-out in the parameter value distribution obtained. The simulation results obtained for $\mathrm{CO}_{2}$ concentration and its distribution in the $\mathrm{BZ}$ and $\mathrm{OZ}$, but also in the PZ and in the total volume of the OT, are in agreement with those provided by recent studies [38] [39]. Results provided in Figure 11 show that there is a significant increase in the $\mathrm{CO}_{2}$ concentration from the fundamental zone BZ, to the OZ but progressively to the PZ and TV.

\subsection{IAQ Indexes}

In this section, some IAQ indexes are computed using simulation results and discussed. The proposed indexes are usually applied for IAQ assessment and a quantitative evaluation of ventilation systems performance with regard to contaminant removal and infection risk control [40]-[42]. Once the distribution of the dependent variables inside the OT, i.e. air velocity, $\mathrm{CO}_{2}$ and particle concentration, were evaluated by simulations, IAQ indexes were calculated. Some of them were expressed in the form of a continuous distribution (local indexes), others refer to the average values of dependent variables in BZ, OZ, PZ and TV. The first investigated IAQ parameter is the mean age of air $(\tau)$ that quantifies the average lifetime of air at a particular location of the room 


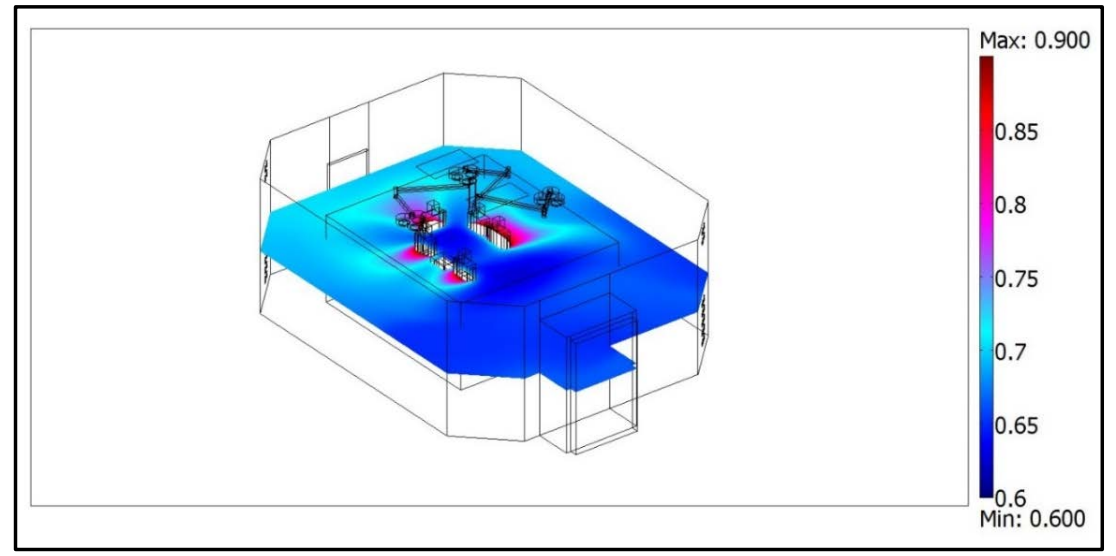

Figure 10. Relative humidity (\%) distribution on horizontal slice $(z=1.2)$.

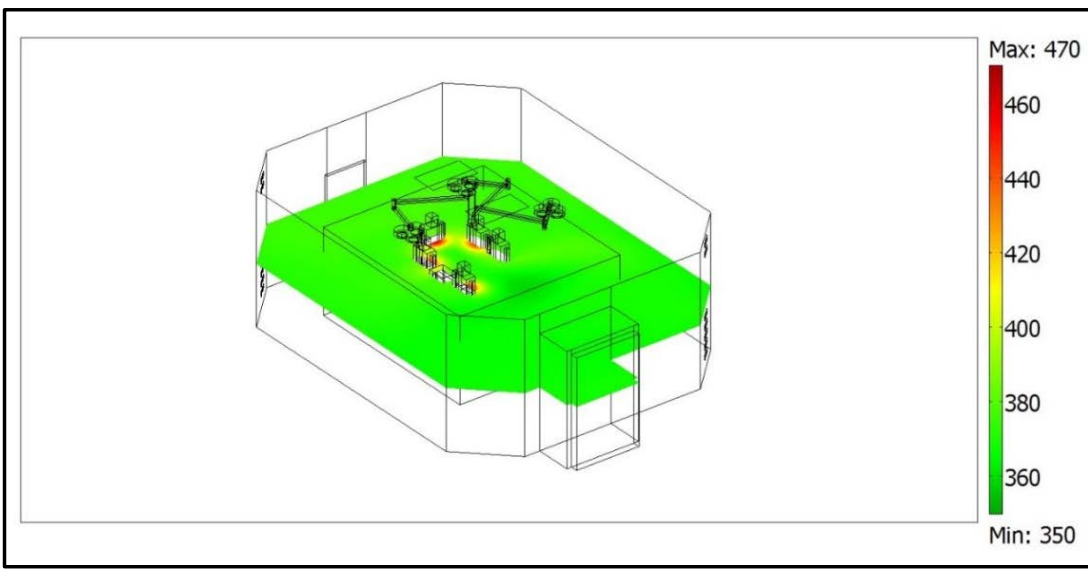

Figure 11. $\mathrm{CO}_{2}$ concentration (ppm) on horizontal slice $(\mathrm{z}=1.2)$.

[43]-[45] for a steady airflow achieved. The air age concept is generally defined as the average time for air to travel from a supply inlet area to any location in a forced ventilated room [46]-[49]. The mean age of air was calculated as well as a dependent variable, as explained in the modelling section. It provides a measure of air freshness, so its lower values are more favorable. At the inlet opening it was assumed to be zero (100\% fresh). The $\tau$ parameter trend was controlled during a transient simulation of 1800 seconds, starting from an initial state corresponding to the steady state condition discussed in the above section. Figure 12 shows a spatial distribution of $\tau$ in a horizontal and in a vertical slice of the room, once the transient time to achieve the steady state is expired. From this figure, it can be pointed out that the lifetime of air located in the central portion of the OT is much lower than that one concerning the peripheral portion of the room.

In order to quantify this result, the average value of $\tau$ was computed in the OT different zones (i.e. BZ, OZ, $\mathrm{PZ}, \mathrm{TV}$ ), and called as $\tau_{Z_{j}}$, where $Z_{j}$ means the generic $j$-zone (Table 6). Generally, these values are quite low. Comparison of these values with the theoretical residence time of air inside the OT (defined as the ratio between the total volume of the room $\left(V_{T V}, \mathrm{~m}^{3}\right)$ and the mass flow rate of incoming ventilating air $\left.\left(\dot{V}_{\text {vent }}, \mathrm{m}^{3} / \mathrm{s}\right)\right)$, shows that the ratio is always higher than 1. Indeed, this comparison consists in computing the following Air Change Efficiency (ACE) index:

$$
\mathrm{ACE}=\frac{V_{T V} / \dot{V}_{v e n t}}{\tau_{Z_{j}}} \times 100
$$

whose values in the different zones are given in Table 6. The ACE index measures how effectively ventilation systems replace the air in a room with fresh air. In the BZ, the average lifetime of air is more than 2 times lower than the theoretical residence time (about 53.7 seconds) that can be deduced analytically. 
Table 6. Values of mean age of air and Air Change Efficiency in the different zones.

\begin{tabular}{ccccc}
\hline & BZ & OZ & TV & PZ \\
\hline$\tau_{\text {ZJ }}[\mathrm{s}]$ & 25.6 & 27.7 & 46.3 & 51.1 \\
ACE [-] & $210 \%$ & $194 \%$ & $116 \%$ & $105 \%$ \\
\hline
\end{tabular}

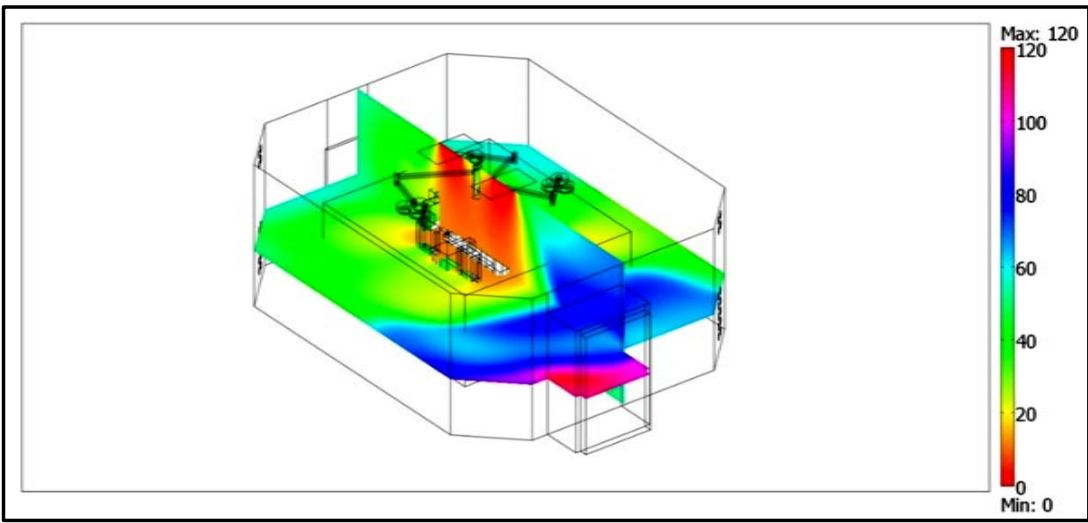

Figure 12. Mean age of air in horizontal $(z=1)$ and vertical $(x=3.0)$ slices.

The Local Air Change Efficiency (LACE) is expressed by the following expression:

$$
\mathrm{LACE}=\frac{V_{T V} / \dot{V}_{\text {vent }}}{\tau} \times 100
$$

The LACE index characterizes the conditions at a specific point (defined as the ratio between the minimum replacement time, as previously defined, and the local mean age of the air). It is possible to observe (Figure 13) that the zone corresponding to the operating table is more favorable from this point of view, reaching LACE values of up to $500 \%-600 \%$.

Knowing the concentration field computed for $\mathrm{CO}_{2}$ and particles, we also assessed the Ventilation Effectiveness (VE) index. The VE index measures how quickly a contaminant is removed from an air volume by quantifying the efficiency with which the internal pollutant is diluted or removed. It depends on the airflow patterns, and is expressed as follows:

$$
\mathrm{VE}=\frac{C_{E}-C_{S}}{C_{Z_{j}}-C_{S}}
$$

where $C_{E}$ is the mean value of contaminant concentration (i.e. $\mathrm{CO}_{2}$ and particles) calculated at the air-recovery grilles (Exhaust), $C_{S}$ is the contaminant concentration at the air inlet diffusers (Supply) and $C_{Z_{j}}$ is the mean value of the contaminant concentration in a specific OT zone (i.e. BZ, OZ, PZ, TV).

Similarly, the Contaminant Removal Effectiveness (CRE) index is defined as the ratio between the concentration of contaminants at the exhaust point and the mean value of contaminant concentration within a specific zone. Its equation is defined as follows:

$$
\mathrm{CRE}=\frac{C_{E}}{C_{Z_{j}}}
$$

Figure 14 shows the VE and CRE indexes computed using $\mathrm{CO}_{2}$ and particle concentrations. Because of particle concentration value was assumed to be zero at the inlet air diffusers $\left(C_{S}=0\right)$, VE and CRE expressions correspond to each other. Because of the very low effect of the settling velocity on particle concentration distribution, a very low quantitative difference was found in computing the CRE (or VE) index as a function of the different particle diameter ranges studied. Therefore, we referred to a single CRE index representative for any particle diameter range studied. Values of the computed global indexes are shown in Figure $14\left(\mathrm{CO}_{2}\right)$ and Figure 15 (particles). The CRE distribution at a specific point that is known as Local Contaminant Removal Effectiveness 


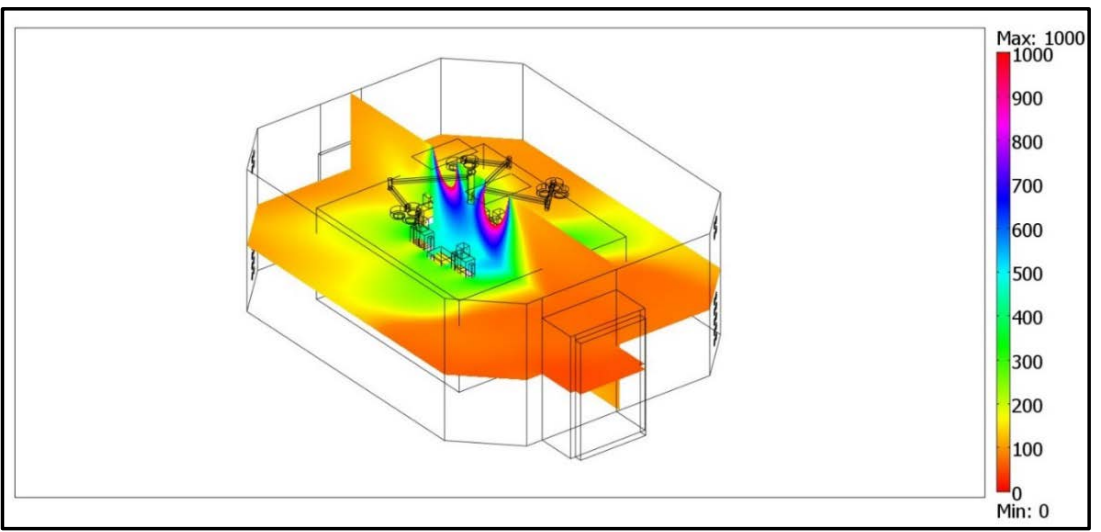

Figure 13. LACE index in horizontal $(z=1.2)$ and vertical slices $(x=3.0)$.

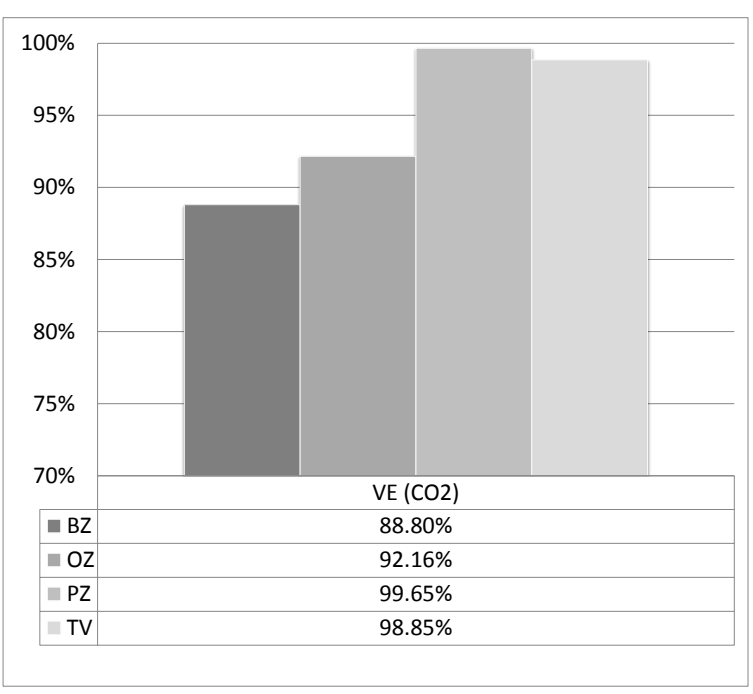

(a)

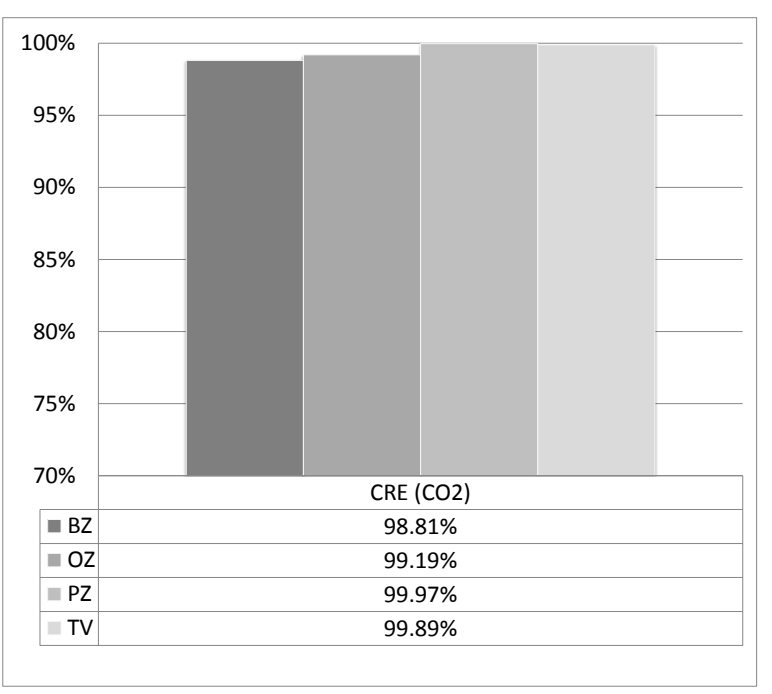

(b)

Figure 14. VE (a) and CRE (b) computed for $\mathrm{CO}_{2}$ concentration in the different zones.

(LCRE) was also calculated by:

$$
\mathrm{LCRE}=\frac{C_{E}}{C}
$$

Local index distributions are shown in Figure 16 for $\mathrm{CO}_{2}$ and in Figure 17 for the particles concentration. Comparison between the LCRE indexes computed for $\mathrm{CO}_{2}$ and particles highlights the combined effect of the two sources (nose for $\mathrm{CO}_{2}$ and body surface for particles) which provides very different trends. The mass transport effect is particularly evident in both cases.

\section{Conclusion}

An experimental and numerical environmental study of a real OT carried out in "at rest" and "operational" conditions allowed the evaluation of the "impact" of medical staff on environmental conditions. Measurements of particle concentration, with and without persons, were exploited in combination with iteratively computed numerical results in order to assess particle emission rate by the occupants for given particle dimensions. Particle concentration fields were also numerically solved for several particle diameters, by using an Euler approach based on the Cunningham formulation of settling velocity. Numerical results were successfully checked against the experimental evidence. $\mathrm{CO}_{2}$ concentration levels numerically computed in the OT agree well with data reported in the literature for similar applications. Some consolidated indexes adopted for monitoring the IAQ were computed for gaseous contaminant $\left(\mathrm{CO}_{2}\right)$ and particle concentration, both in terms of spatial distribution and 


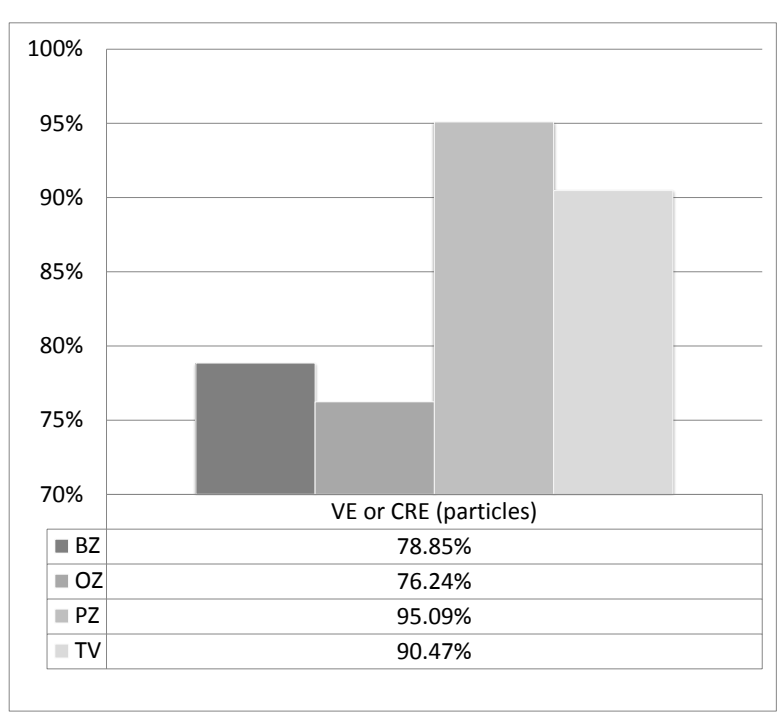

Figure 15. VE (or CRE) computed for particles concentration in the different zones.

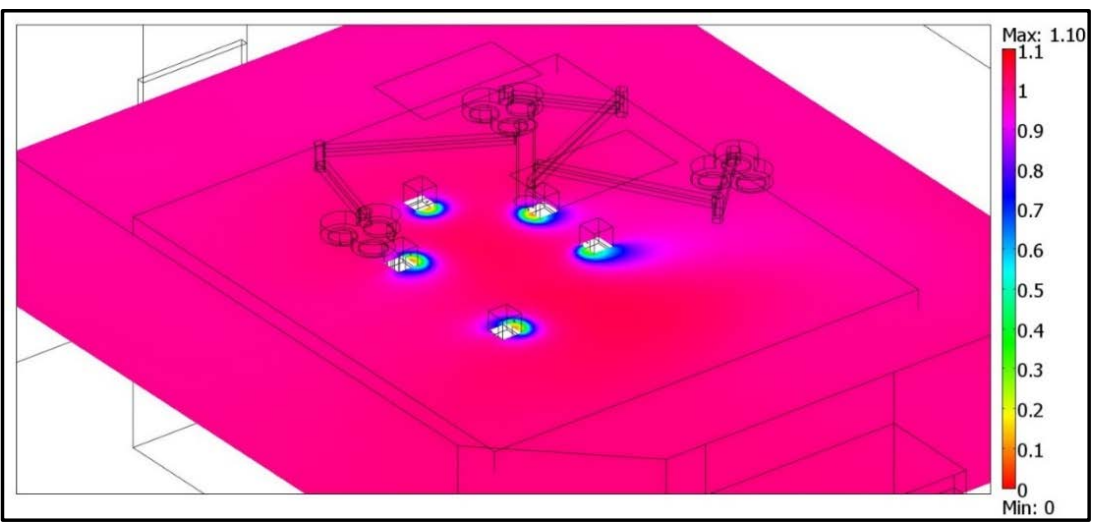

Figure 16. LCRE for $\mathrm{CO}_{2}$ in a horizontal slice $(z=1.6)$.

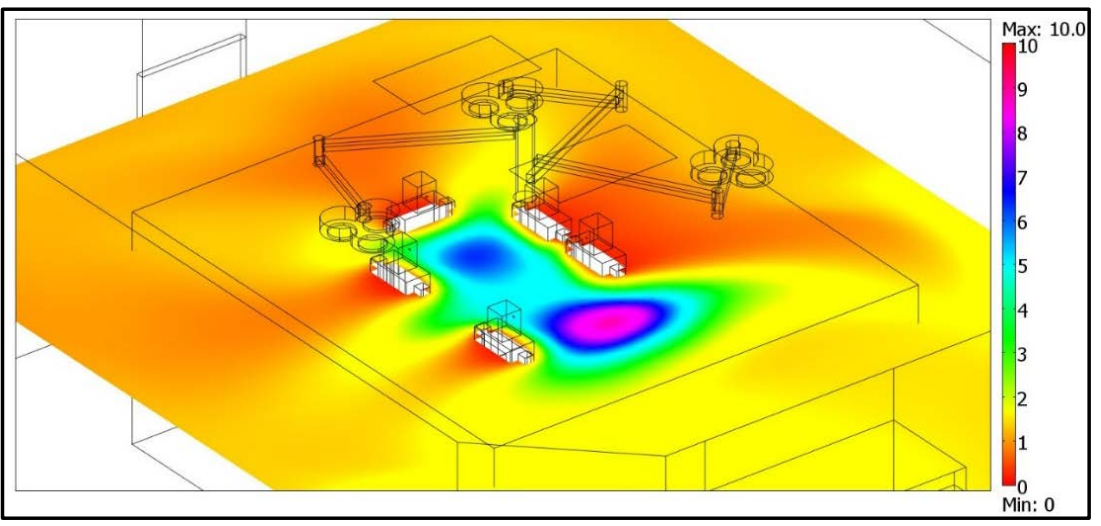

Figure 17. LCRE for particles concentration in a horizontal slice $(z=1.4)$.

overall values referring to specific OT zones. Results obtained by applying our proposed methodology for estimating the particle emission rate in indoor environments highlight a good agreement with the few number contributions in the literature concerning particle emission for different diameters. Our study contributes to better understanding the additional environmental "load" induced by the medical staff in an OT, based on an innovative strategy proposed and applied to quantify the particle emission rate released by occupants for given ranges 
of particle diameters. The integrated experimental and numerical approach proposed with our present study is in accordance with some recent surgical infection control guidelines that highlight the importance of the surgical staff behaviour control in order to decrease air contamination and wound colonisation. These recommendations include restricting the movements and the number of persons in the OT, but they are often general and based on expert advice.

\section{References}

[1] Chow, T.T. and Wang, J. (2012) Dynamic Simulation on Impact of Surgeon Bending Movement on Bacteria-Carrying Particles Distribution in Operating Theatre. Building and Environment, 57, 68-80. http://dx.doi.org/10.1016/j.buildenv.2012.04.010

[2] Brohus, H, Balling, K.D. and Jeppesen, D. (2006) Influence of Movements on Contaminant Transport in an Operating Room. Indoor Air, 16, 356-372. http://dx.doi.org/10.1111/j.1600-0668.2006.00454.X

[3] Franke, J.E. and Wadden, R.A. (1987) Indoor Contaminant Emission Rates Characterized by Source Activity Factors. Environmental Science and Technology, 21, 45-51. http://dx.doi.org/10.1021/es00155a004

[4] Friberg, B., Friberg, S., Östensson, R. and Burman, L.G. (2001) Surgical Area Contamination-Comparable Bacterial Counts Using Disposable Head and Mask and Helmet Aspirator System, but Dramatic Increase upon Omission of Head-Gear: An Experimental Study in Horizontal Laminar Air-Flow. Journal of Hospital Infection, 47, 110-115. http://dx.doi.org/10.1053/jhin.2000.0909

[5] Saidi, M.H., Sajadi, B. and Molaeimanesh, G.R. (2011) The Effect of Source Motion On Contaminant Distribution in the Cleanrooms. Energy and Buildings, 43, 966-970.

[6] Hospodsky, D., Qian, J, Nazaroff, W.W., Yamamoto, N., Bibby, K., Yazdi, H.R. and Peccia, J. (2012) Human Occupancy as a Source of Indoor Airborne Bacteria. PLOS One Sources of Indoor Airborne Bacteria, 7, 1-10.

[7] Mackintosh, C.A., Lidwell, O.M., Towers, A.G. and Marples, R.R. (1978) The Dimensions of Skin Fragments Dispersed into the Air during Activity. The International Journal of Hygiene and Environmental Health, 81, 471-480. http://dx.doi.org/10.1017/S0022172400025341

[8] Nazaroff, W.W. (2004) Indoor Particle Dynamics. Indoor Air, 7, 175-183. http://dx.doi.org/10.1111/j.1600-0668.2004.00286.x

[9] Li, C.-S. and Hou, P.-A. (2003) Bioaerosol Characteristics in Hospital Clean Rooms. The Science of the Total Environment, 305, 169-176. http://dx.doi.org/10.1016/S0048-9697(02)00500-4

[10] Pasquarella, C., Sansebastiano, G.E., Ferretti, S., Saccani, E., Fanti, M., Moscato, U., Giannetti, G., Fornia, S., Cortellini, P., Vitali, P. and Signorelli C. (2007) A Mobile Laminar Airflow Unit to Reduce Air Bacterial Contamination at Surgical Area in a Conventionally Ventilated Operating Theatre. Journal of Hospital Infection, 66, 313-319. http://dx.doi.org/10.1016/j.jhin.2007.05.022

[11] Yu, B.F., Hu, Z.B., Liu, M., Yang, H.L., Kong, Q.X. and Liu, Y.H. (2009) Review of Research on Air-Conditioning Systems and Indoor Air Quality Control for Human Health. International Journal of Refrigeration, 32, 3-20. http://dx.doi.org/10.1016/j.ijrefrig.2008.05.004

[12] Faulkner, D., Fisk, W.J., Sullivan, D.P. and Lee, S.M. (2004) Ventilation Efficiencies and Thermal Comfort Results of a Desk-Edge-Mounted Task Ventilation System. Indoor Air, 14, 92-97. http://dx.doi.org/10.1111/j.1600-0668.2004.00295.x

[13] Niu, J.L., Gao, N.P., Ma, P. and Zuo, H.G. (2007) Experimental Study on a Chair-Based Personalized Ventilation System. Building and Environment, 42, 913-925. http://dx.doi.org/10.1016/j.buildenv.2005.10.011

[14] Zhao, B. and Guan, P. (2007) Modeling Particle Dispersion in Personalized Ventilated Room. Building and Environment, 42, 1099-1109. http://dx.doi.org/10.1016/j.buildenv.2005.11.009

[15] Chow, T.T. and Yang, X.Y. (2005) Ventilation Performance in the Operating Theatre against Airborne Infection: Numerical Study on an Ultra-Clean System. Journal of Hospital Infection, 59, 138-147. http://dx.doi.org/10.1016/j.jhin.2004.09.006

[16] Chow, T.T. and Yang, X.Y. (2003) Performance of Ventilation System in a Non-Standard Operating Room. Building and Environment, 38, 1401-1411. http://dx.doi.org/10.1016/S0360-1323(03)00155-0

[17] Chen, F.Z., Yu, S.C.M. and Lai, A.C.K. (2006) Modeling Particle Distribution and Deposition in Indoor Environments with a New Drift-Flux Model. Atmospheric Environment, 40, 357-367. http://dx.doi.org/10.1016/j.atmosenv.2005.09.044

[18] Gao, N.P. and Niu, J.L. (2007) Modeling Particle Dispersion and Deposition in Indoor Environments. Atmospheric Environment, 41, 3862-3876. http://dx.doi.org/10.1016/j.atmosenv.2007.01.016 
[19] Qian, J., Hospodsky, D., Yamamoto, N., Nazaroff, W.W. and Peccia, J. (2012) Size-Resolved Emission Rates of Airborne Bacteria and Fungi in an Occupied Classroom. Indoor Air, 22, 339-351. http://dx.doi.org/10.1111/j.1600-0668.2012.00769.X

[20] Zhao, B., Zhang, Y., Li, X.T., Yang, X.D. and Huang, D.T. (2004) Comparison of Indoor Aerosol Particle Concentration and Deposition in Different Ventilated Rooms by Numerical Method. Building and Environment, 39, 1-8. http://dx.doi.org/10.1016/j.buildenv.2003.08.002

[21] Balocco, C., Petrone, G. and Cammarata, G. (2012) Assessing the Effects of Sliding Doors on an Operating Theatre Climate. Building Simulation, 5, 73-83. http://dx.doi.org/10.1007/s12273-012-0071-x

[22] ANSI/ASHRAE Standard 62.1-2007 (2007) Ventilation for Acceptable Indoor Air Quality.

[23] UNI EN ISO 14644-3 2006 (2006) Cleanrooms and Associated Controlled Environments—Part 3: Test Methods.

[24] UNI EN ISO 14644-1 2006 (2006) Cleanrooms and Associated Controlled Environments. Part 1: Classification of Air Cleanliness.

[25] UNI EN ISO 14644-2 2006 (2006) Cleanrooms and Associated Controlled Environments Part 2: Specifications for Testing and Monitoring to Prove Continued Compliance with ISO 14644-1.

[26] ISO 21501-4:2007 (2007) Determination of Particle Size Distribution—Single Particle Light Interaction Methods. Part 4: Light Scattering Airborne Particle Counter for Clean Spaces.

[27] UNI 11425 (2011) Surgery Operating Theatre, Ventilation and Air-Conditioning System for Contamination Control (VCCC)—Design, Construction, Commissioning, Qualification, Management and Maintenance (in Italian)

[28] Hinze, J.O. (1975) Turbulence. 2nd Edition, McGraw Hill, New York.

[29] Deuflhard, P. (1974) A Modified Newton Method for the Solution of Ill-Conditioned Systems of Nonlinear Equations with Application to Multiple Shooting. Numerische Mathematik, 22, 289-315. http://dx.doi.org/10.1007/BF01406969

[30] Hindmarsh, H., Brown, A.C., Grant, P.N., Lee, K.E., Serban, S.L., Shumaker, R., Woodward, D.E. and Woodward C.S. (2005) SUNDIALS: Suite of Nonlinear and Differential/Algebraic Equation Solvers. ACM Transactions on Mathematical Software, 31, 363-396. http://dx.doi.org/10.1145/1089014.1089020

[31] ONORM H 6020 (2007) Ventilation and Air Conditioning Plants for Locations for Medical Use-Design, Construction, Operation, Maintenance, Technical and Hygienic Inspections.

[32] VDI 2167, Part 1 (2004) Building Services in Hospitals-Heating, Ventilationandair-Conditioning.

[33] DPR 14/01/97 (1997) Approvazione Dell'atto di Indirizzo e Coordinamento alle Regioni e alle Province Autonome di Trento e di Bolzano, in Materia di Requisiti Strutturali, Tecnologici ed Organizzativi Minimi per L'esercizio Delle Attività Sanitaria da Parte Delle Strutture Pubbliche e Private. In: G.U.R.I. 20/02/1997 n.42 (in Italian).

[34] ISPESL (2009) Dipartimento Igiene del Lavoro, Linee guida per la definizione degli standard di sicurezza e di igiene ambientale dei reparti operatori. (In Italian) http://www.ispesl.it/

[35] NBHF (2004) Building Guidelines for a Surgical Department.

[36] HTM 03-01 (2007) Heating and Ventilation Systems Health Technical Memorandum 03-01: Specialised Ventilation for Healthcare Premises, Part A: Design and Validation. TSO, Edinburgh.

[37] ANSI/ASHRAE 170 (2008) Ventilation of Health Care Facilities.

[38] Karthikeyan, C.P. and Samuel, A.A. (2008) $\mathrm{CO}_{2}$-Dispersion Studies in an Operation Theatre under Transient Conditions. Energy and Buildings, 40, 231-239.

[39] Al-Waked, R. (2010) Effect of Ventilation Strategies on Infection Control inside Operating Theatres. Engineering Applications of Computational Fluid Mechanics, 4, 1-16.

[40] Villafruela, J.M., Castro, F., San José, J.F. and Saint-Martin, J. (2013) Comparison of Air Change Efficiency, Contaminant Removal Effectiveness and Infection Risk as IAQ Indices in Isolation Rooms. Energy and Buildings, 57, 210219. http://dx.doi.org/10.1016/j.enbuild.2012.10.053

[41] Kwon, K.S., Lee, I.B., Han, H.T., Shin, C.Y., Hwang, H.S., Hong, S.W., Bitog, J.P., Seo, I.H. and Han, C.P. (2011) Analysing Ventilation Efficiency in a Test Chamber Using Age-of-Air Concept and CFD Technology. Biosystems Engineering, 110, 421-433. http://dx.doi.org/10.1016/j.biosystemseng.2011.08.013

[42] Meiss, A., Feijó-Muñoz, J. and Garcia-Fuentes, M.A. (2013) Age-of-the-Air in Rooms According to the Environmental Condition of Temperature: A Case Study. Energy and Buildings, 67, 88-96. http://dx.doi.org/10.1016/j.enbuild.2013.08.016

[43] Abanto, J., Rarrero, D., Reggio, M. and Ozell, B. (2004) Air Flow Modelling in a Computer Room. Building and Environment, 39, 1393-1402. http://dx.doi.org/10.1016/j.buildenv.2004.03.011

[44] Zhang, L., Chow, T.T., Fong, K.F., Tsang, C.F. and Wang, Q.W. (2005) Comparison of Performances of Displacement 
and Mixing Ventilations. Part II: Indoor Air Quality. International Journal of Refrigeration, 28, 288-305. http://dx.doi.org/10.1016/j.ijrefrig.2004.04.006

[45] Petrone, G., Cammarata, L. and Cammarata, G. (2011) A Multi-Physical Simulation on the IAQ in a Movie Theatre Equipped by Different Ventilating Systems. Building Simulation: An International Journal, 4, 21-31.

[46] Sandberg, M. and Sjöberg, M. (1983) The Use of Moments for Assessing Air Quality in Ventilated Rooms. Building and Environment, 18, 181-197. http://dx.doi.org/10.1016/0360-1323(83)90026-4

[47] Federspiel, C.C. (1999) Air-Change Effectiveness: Theory and Calculation Methods. Indoor Air, 9, 47-56. http://dx.doi.org/10.1111/j.1600-0668.1999.t01-3-00008.x

[48] Li, X.T., Li, D.N., Yang, X.D. and Yang, J.R. (2003) Total Air Age: An Extension of the Air Age Concept. Building and Environment, 38, 1263-1269. http://dx.doi.org/10.1016/S0360-1323(03)00133-1

[49] Mendez, C., San José, J.F., Villafruela, J.M. and Castro, F. (2008) Optimization of a Hospital Room by Means of CFD for More Efficient Ventilation. Energy and Buildings, 40, 849-854. http://dx.doi.org/10.1016/j.enbuild.2007.06.003 
Scientific Research Publishing (SCIRP) is one of the largest Open Access journal publishers. It is currently publishing more than 200 open access, online, peer-reviewed journals covering a wide range of academic disciplines. SCIRP serves the worldwide academic communities and contributes to the progress and application of science with its publication.

Other selected journals from SCIRP are listed as below. Submit your manuscript to us via either submit@scirp.org or Online Submission Portal.
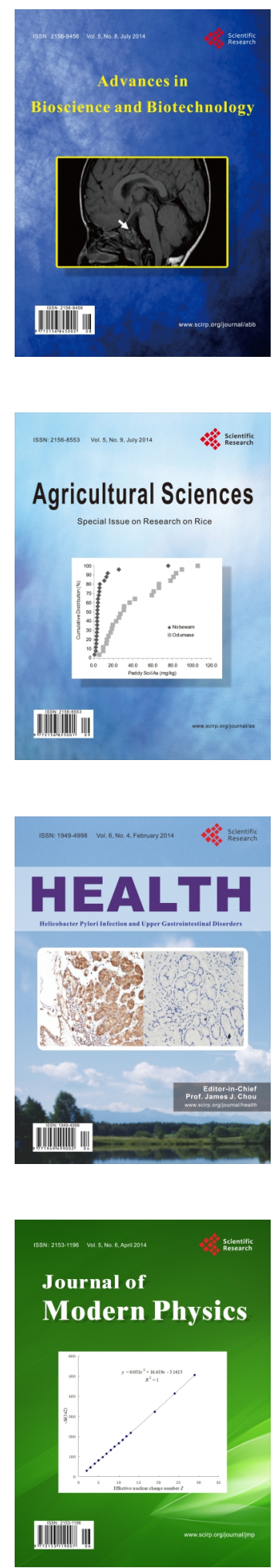
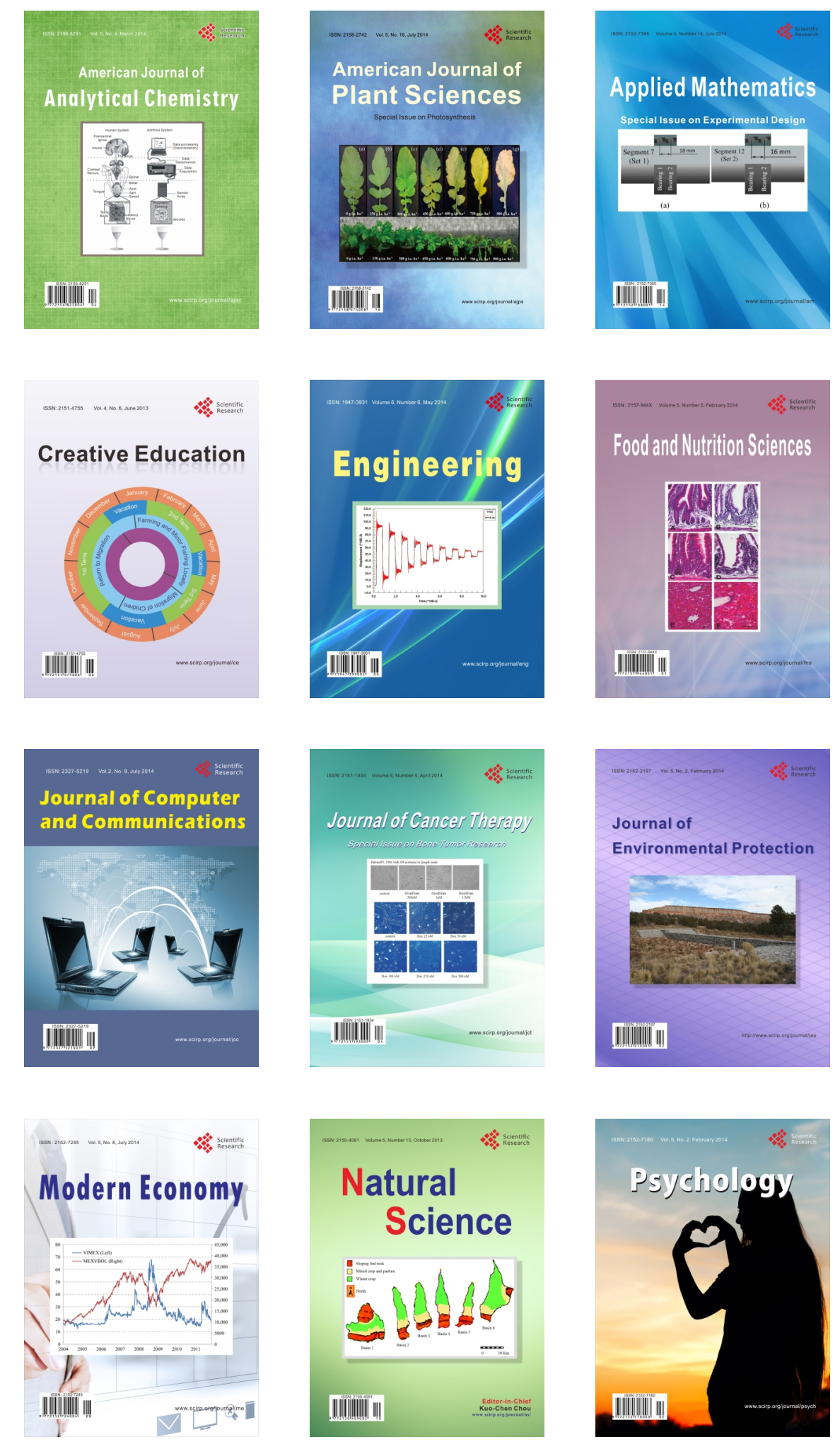